\title{
Evaluation of Corn Inbreds and Advanced Breeding Lines for Resistance to Aflatoxin Contamination in the Field
}

\author{
G. L. Windham and W. P. Williams, USDA-ARS, Corn Host Plant Resistance Research Unit, Mississippi State, \\ MS 39762
}

\section{ABSTRACT}

Windham, G. L., and Williams, W. P. 2002. Evaluation of corn inbreds and advanced breeding lines for resistance to aflatoxin contamination in the field. Plant Dis. 86:232-234.

Eighteen corn inbred lines and advanced breeding lines were evaluated for resistance to aflatoxin contamination when artificially inoculated with Aspergillus flavus in 1998, 1999 (two tests), and 2000 at Mississippi State, MS, in field studies. The top ear of each plant was inoculated with the A. flavus isolate NRRL 3357 seven days after midsilk (50\% of the plants in a plot had silks emerged) using the side-needle technique. Ears were harvested at kernel maturity approximately 63 days after midsilk and aflatoxin levels were measured using the Vicam AflaTest. Aflatoxin contamination in the inbreds was extremely high in 1998. Levels ranged from 139 to $21,090 \mathrm{ng} / \mathrm{g}$. In 1999 , aflatoxin contamination ranged from 17 to $1,070 \mathrm{ng} / \mathrm{g}$ in one test and 14 to $1,278 \mathrm{ng} / \mathrm{g}$ in another test. In 2000, aflatoxin levels ranged from 237 to $7,503 \mathrm{ng} / \mathrm{g}$. Lines that supported lowest levels of aflatoxin contamination included Mp81:112, Mp92:673, Mp92:679, and Mp494. These lines provide potential new sources of resistance that can be used to move aflatoxin resistance into commercial corn hybrids.

Additional keywords: Aspergillus flavus, maize, mycotoxin, resistance, Zea mays

Aflatoxin is a naturally occurring toxin produced by the fungus Aspergillus flavus. This toxin is the most potent carcinogen found in nature $(3,8,10)$. Dietary exposure to aflatoxin is one of the major causes of hepatocellular carcinoma, which is the fifth most common cancer in the world (20). Individuals with hepatitis $B$ viral infection that consume aflatoxincontaminated corn or peanuts have a particularly high risk for developing hepatocellular carcinoma (20).

In the United States, aflatoxin contamination of corn grain occurs sporadically in the Midwest, but is a chronic problem in the Southeast $(5,9,17)$. In 1998, a major aflatoxin outbreak in corn occurred in the southeastern United States. Producer losses ranged from $\$ 85$ million to $\$ 100$ million in Arkansas, Louisiana, Mississippi, and Texas. Higher than normal temperatures, drought conditions, insect damage, and

Corresponding author: G. L. Windham

E-mail: gwindham@ra.msstate.edu

Contribution of the Crop Science Research Laboratory, USDA-ARS, in cooperation with the Mississippi Agricultural and Forestry Experiment Station. Published with the approval of both agencies as Paper No. J9793 of the Mississippi Agricultural and Forestry Experiment Station.

Accepted for publication 17 October 2001.

Publication no. D-2002-0102-01R

This article is in the public domain and not copyrightable. It may be freely reprinted with customary crediting of the source. The American Phytopathological Society, 2002. other factors contributed to high levels of aflatoxin in corn grain $(23,24)$.

The U. S. Food and Drug Administration limits the sale of grain with aflatoxin levels exceeding $20 \mathrm{ng} / \mathrm{g}$ (8). Such grain cannot be shipped across state lines and can be used only for livestock feed. Once corn is found to be contaminated with aflatoxin very few detoxification and utilization options are available for growers.

The best strategy to reduce aflatoxin contamination is to limit toxin accumulation in the developing corn grain. Cultural control practices such as using adapted varieties, irrigation, early planting dates, and optimal fertilization can minimize aflatoxin contamination most years $(9,17)$. However, no control strategy is completely effective when environmental conditions are extremely favorable for growth of the fungus.

The most desirable method of aflatoxin control is through host plant resistance to A. flavus infection and subsequent aflatoxin accumulation. Unfortunately, no commercial hybrids have been identified that are resistant to A. flavus $(18,23)$. Corn inbreds $(2,12,19)$, single cross hybrids (14), populations (16), and open-pollinated varieties (25) have been evaluated for resistance to A. flavus. Three corn inbreds, Mp313E (13), Mp420 (15), and Mp715 (21), were identified as sources of resistance and released to the public. Improved sources of resistance still are needed to eliminate aflatoxin contamination in corn. The objective of this study was to evaluate corn inbreds and advanced breeding lines for aflatoxin accumulation when develop- ing ears were inoculated artificially with $A$. flavus in the field.

\section{MATERIALS AND METHODS}

Eighteen corn inbred lines and advanced breeding lines were evaluated for aflatoxin accumulation in four tests over a 3 year period at the Plant Science Research Farm, Mississippi State, Mississippi. Corn lines were planted 13 April 1998, 21 April (test 1) and 23 April (test 2) 1999, and 21 April 2000. Inbreds used as resistant checks in the tests included Mp313E, Mp715, and Tx601 $(12,13,21,22)$. In all tests, a randomized complete block design was utilized with four replications. Plots consisted of 20 plants in single rows that were $5.1 \mathrm{~m}$ long and spaced $0.96 \mathrm{~m}$ apart. Supplemental irrigation was provided during the growing season to limit drought stress and to aid in grain production.

A. flavus isolate NRRL 3357, which is known to produce high levels of aflatoxin in corn grain (12), was used as inoculum in all tests. Inoculum was increased on sterile corncob grits in 500-ml flasks each containing $50 \mathrm{~g}$ of grits and $100 \mathrm{ml}$ of $\mathrm{H}_{2} \mathrm{O}$, and incubated at $28^{\circ} \mathrm{C}$ for 3 weeks. Conidia were washed from the grits using 500 $\mathrm{ml}$ sterile distilled water containing 20 drops of Tween 20 per liter and filtered through four layers of sterile cheesecloth. The concentrations of conidia were determined with a hemacytometer and adjusted with sterile distilled water to $9 \times 10^{7}$ conidia/ml. Inoculum not used immediately was refrigerated at $4^{\circ} \mathrm{C}$. Corn lines were inoculated 7 days after midsilk (50\% of plants in a plot had silks emerged) using the side-needle technique (26). The top ear of each plant was inoculated with a 3.4-ml suspension containing $3 \times 10^{8}$ A. flavus conidia.

All inoculated ears in each plot were harvested by hand at kernel maturity approximately 63 days after midsilk and dried at $38^{\circ} \mathrm{C}$ for 7 days. Ears were then machine shelled, and grain samples from each row were poured into a sample splitter twice to mix the grain. Samples were ground using a Romer mill (Union, MO). Aflatoxin contamination in a $50 \mathrm{~g}$ subsample from each plot was determined using the Vicam Aflatest (Watertown, MA). This procedure can detect aflatoxins $\left(B_{1}, B_{2}, G_{1}\right.$, $\mathrm{G}_{2}$ ) at concentrations as low as $1 \mathrm{ng} / \mathrm{g}$.

Logarithmic transformation was used on all aflatoxin data to stabilize variance of the data. Data were subjected to analysis of variance with the SAS general linear mod- 
els procedure (SAS Institute, Cary, NC). Means were compared by the least significant difference test (LSD) at $P=0.05$. All aflatoxin data are reported as geometric means (antilogarithm of the logarithmic mean).

\section{RESULTS AND DISCUSSION}

In 1998, aflatoxin levels were extremely high in most of the corn inbreds and breeding lines evaluated with levels ranging from 139 to $21,090 \mathrm{ng} / \mathrm{g}$ (Table 1). The mean aflatoxin contamination for the test was $3,959 \mathrm{ng} / \mathrm{g}$. Lines with aflatoxin levels significantly $(P=0.05)$ lower than the resistant check, Tx601, were Mp81:112, Mp92:673, and Mp92:679.

In 1999, aflatoxin levels in two separate tests were much lower than in 1998. Aflatoxin levels ranged from 17 to $1,070 \mathrm{ng} / \mathrm{g}$ in test 1 , and the mean level of aflatoxin contamination was $189 \mathrm{ng} / \mathrm{g}$. Lines in test 1 with aflatoxin levels comparable to the resistant checks, Mp715 and Mp313E, were Mp81:112, Mp92:973, and Mp92:679. In test 2, aflatoxin levels ranged from 14 to $1,278 \mathrm{ng} / \mathrm{g}$, and the mean aflatoxin contamination was $349 \mathrm{ng} / \mathrm{g}$. Mp440 had aflatoxin levels statistically similar to the resistant checks, Mp313E and Mp715. Mp494 had aflatoxin levels that were significantly $(P=0.05)$ lower than the resistant check, Mp313E, and aflatoxin levels statistically similar to the resistant check, Mp715.

In 2000, aflatoxin levels ranged from 237 to $7,503 \mathrm{ng} / \mathrm{g}$, and the mean level of aflatoxin contamination in the study was $1,554 \mathrm{ng} / \mathrm{g}$. Lines with aflatoxin levels statistically similar to the resistant check, Tx601, included Mp80:04, Mp81:112, Mp92:673, Mp92:679, and Mp494.

To determine the resistance of corn genotypes to aflatoxin contamination in the field, ears must be inoculated with $A$. flavus spores 1 to 3 weeks after silk emergence (22). Natural infection of developing ears by A. flavus is sporadic from year to year and can yield misleading data in aflatoxin resistance evaluations. The sideneedle technique has become our standard inoculation technique in field evaluations. Although a labor-intensive procedure, it has provided more consistent results than other techniques $(22,26)$. This technique is a fairly harsh inoculation method when compared to natural infection (26). When the needle is inserted between the ear and the husk normally two to three kernels are wounded, providing the fungus with an entry into the ear. Inbreds, which demonstrate resistance under these conditions may be even more resistant to A. flavus under natural infection.

Aflatoxin levels over the 3 year period varied considerably. The inoculation technique and isolate used remained the same over the study period. However, environmental conditions most notably ambient temperature, varied across the 3 years. In
1998, maximum daily ambient air temperatures during the silking period in late June and early July were much higher than in 1999 or 2000 (Fig. 1). High ambient air temperatures during early ear development may play an important role in A. flavus infection and subsequent aflatoxin con-

tamination. In 1999, ambient air temperatures followed a more typical pattern and aflatoxin levels in both tests were much lower. In 2000, higher ambient temperatures during the latter part of the growing season may have contributed to higher aflatoxin levels than those observed in

Table 1. Aflatoxin contamination of corn inbreds and advanced breeding lines grown in the field and artificially inoculated with Aspergillus flavus at Mississippi State, MS, from 1998 to 2000

\begin{tabular}{lcccc}
\hline & \multicolumn{4}{c}{ Aflatoxin $^{\mathbf{y}} \mathbf{( n g / g )}$} \\
\cline { 2 - 5 } Genotype & $\mathbf{1 9 9 8}$ & $\mathbf{1 9 9 9 / T e s t ~ 1 ~}$ & $\mathbf{1 9 9 9 / T e s t ~ 2}$ & $\mathbf{2 0 0 0}$ \\
\hline Ab24E & $4,436 \mathrm{bc}$ & - & $231 \mathrm{~cd}$ & - \\
GA209 & - & - & $1,278 \mathrm{a}$ & $2,510 \mathrm{~b}$ \\
Mp80:04 & - & $89 \mathrm{~cd}$ & $176 \mathrm{de}$ & $237 \mathrm{e}$ \\
Mp81:112 & $421 \mathrm{ef}$ & $36 \mathrm{de}$ & - & $346 \mathrm{de}$ \\
Mp92:673 & $139 \mathrm{f}$ & $19 \mathrm{e}$ & - & $253 \mathrm{e}$ \\
Mp92:679 & $268 \mathrm{ef}$ & $36 \mathrm{de}$ & - & $732 \mathrm{~cd}$ \\
Mp95:535 & $595 \mathrm{de}$ & $381 \mathrm{ab}$ & - & - \\
Mp313E & - & $18 \mathrm{e}$ & $70 \mathrm{ef}$ & - \\
Mp339 & $5,794 \mathrm{~b}$ & - & $536 \mathrm{abc}$ & $1,613 \mathrm{bc}$ \\
Mp440 & $2,330 \mathrm{bc}$ & - & $66 \mathrm{ef}$ & - \\
Mp494 & - & $72 \mathrm{~cd}$ & $14 \mathrm{~g}$ & $342 \mathrm{de}$ \\
Mp496 & - & $229 \mathrm{bc}$ & $720 \mathrm{ab}$ & - \\
Mp713 & - & $234 \mathrm{bc}$ & $278 \mathrm{bcd}$ & - \\
Mp714 & - & $159 \mathrm{bc}$ & $248 \mathrm{bcd}$ & - \\
Mp715 & - & $17 \mathrm{e}$ & $39 \mathrm{fg}$ & - \\
SC212m & $21,090 \mathrm{a}$ & $1,070 \mathrm{a}$ & $538 \mathrm{abc}$ & $7,503 \mathrm{a}$ \\
Tx601 & $1,529 \mathrm{~cd}$ & - & - & $457 \mathrm{de}$ \\
Va35 & $2,997 \mathrm{bc}$ & $105 \mathrm{~cd}$ & - & - \\
\hline
\end{tabular}

${ }^{\mathrm{y}}$ The antilogarithm of the logarithmic mean. Means followed by different letters are significantly different at the 0.05 probability level by the least significant difference test.

${ }^{\mathrm{z}}$ No data available.

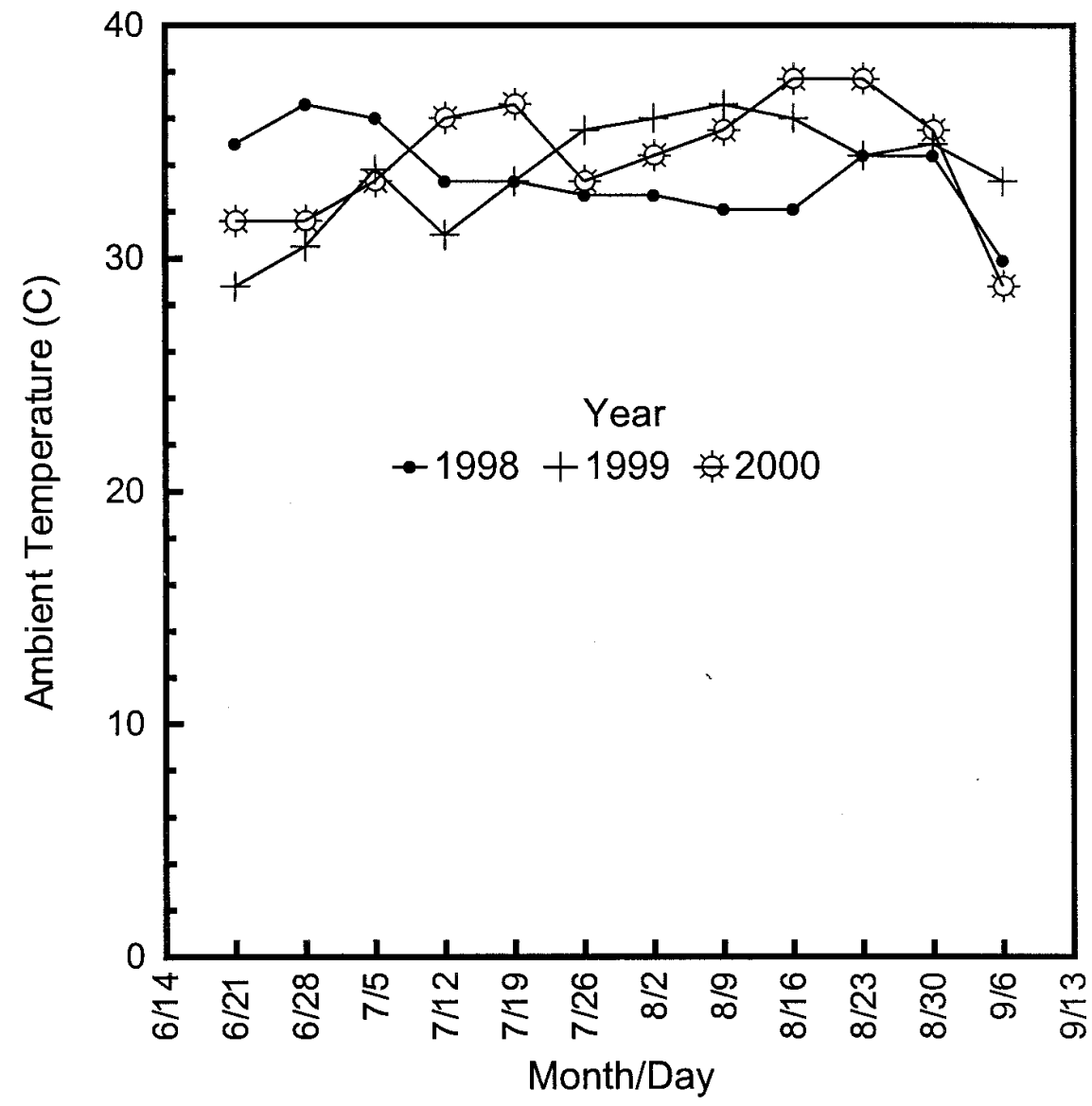

Fig. 1. Mean ambient air maximum temperatures during ear development at Mississippi State, MS, for 1998,1999 , and 2000 . 
1999. Other factors may have influenced aflatoxin levels, but ambient air temperature probably had considerable influence on aflatoxin contamination. A. flavus growth is favored by temperatures of $35^{\circ} \mathrm{C}$ or greater (5). These temperatures were reached all three growing seasons. The stage of ear development when high temperatures are present may play a key role in A. flavus infection and subsequent aflatoxin production. Soil moisture levels probably did not affect aflatoxin levels in any of the studies. Plants in all tests were provided with supplemental irrigation during the growing season to prevent drought stress and to aid in grain production.

Progress has been made in identifying sources of resistance to A. flavus infection and aflatoxin contamination in corn $(1,2,13,15)$. The exact nature of resistance of these lines has not been clearly delineated, but several external and internal factors, which may contribute toward resistance, have been identified. Kernels of some resistant genotypes have a thick waxy covering not observed in susceptible genotypes (11). Differences in kernel proteins have also been observed between resistant and susceptible corn inbreds $(6,7)$. A $14-\mathrm{kDa}$ protein was found in higher concentrations in resistant inbreds than in susceptible inbreds (4). Research needs to continue in these areas to identify kernel characteristics that deter A. flavus kernel infection and subsequent aflatoxin contamination. Corn lines in our studies that supported low levels of aflatoxin may have internal or external kernel characteristics that have not been identified in genotypes previously reported to be resistant to $A$. flavus.

Lines which showed resistance to aflatoxin contamination included Mp81:112, Mp92:673, Mp92:679, and Mp494. These lines provide potential new sources of resistance that can be used to move resistance into commercial corn hybrids.

\section{ACKNOWLEDGMENTS}

The authors gratefully acknowledge the excellent technical assistance of Mike Alpe, Paul Buckley, Gerald A. Matthews, Jr., LaDonna Owens, and E. Lee Scruggs.

\section{LITERATURE CITED}

1. Brown, R. L., Chen, Z.-Y., Cleveland, T. E., and Russin, J. S. 1999. Advances in the development of host resistance in corn to aflatoxin contamination by Aspergillus flavus. Phytopathology 89:113-117.

2. Campbell, K. W., and White, D. G. 1995. Evaluation of corn genotypes for resistance to Aspergillus ear rot, kernel infection, and aflatoxin production. Plant Dis. 79:1039-1045.

3. Castegnaro, M., and McGregor, D. 1998. Carcinogenic risk assessment of mycotoxins. Rev. Med. Vet. 149:671-678.

4. Chen, Z.-Y., Brown, R. L., Lax, A. R., Guo, B. Z., Cleveland, T. E., and Russin, J. S. 1998. Resistance to Aspergillus flavus in corn kernels is associated with a 14-kDa protein. Phytopathology 88:276-281.

5. Diener, U. L., Cole, R. J., Sanders, T. H., Payne, G. A., Lee, L. S., and Klich, M. A. 1987. Epidemiology of aflatoxin formation by Aspergillus flavus. Annu. Rev. Phytopathol. 25:249-270.

6. Guo, B. Z., Brown, R. L., Lax, A. R., Cleveland, T. E., Russin, J. S., and Widstrom, N. W. 1998. Protein profiles and antifungal activities of kernel extracts from corn genotypes resistant and susceptible to Aspergillus flavus. J. Food Prot. 61:98-102.

7. Huang, Z., White, D. G., and Payne, G. A. 1997. Corn seed proteins inhibitory to Aspergillus flavus and aflatoxin biosynthesis. Phytopathology 87:622-627.

8. Park, D. L., and Liang, B. 1993. Perspectives on aflatoxin control for human food and animal feed. Trends Food Sci. Technol. 4:334342.

9. Payne, G. A. 1992. Aflatoxins in maize. Crit. Rev. Plant Sci. 10:423-440.

10. Pittet, A. 1998. Natural occurrence of mycotoxins in foods and feeds - an updated review. Rev. Med. Vet. 149:479-492.

11. Russin, J. S., Guo, B. Z., Tubajika, K. M., Brown, R. L., Cleveland, T. E., and Widstrom, N. W. 1997. Comparison of kernel wax from corn genotypes resistant or susceptible to Aspergillus flavus. Phytopathology 87:529-533.

12. Scott, G. E., and Zummo, N. 1988. Sources of resistance in maize to kernel infection by Aspergillus flavus in the field. Crop Sci. 28:504-507.

13. Scott, G. E., and Zummo, N. 1990. Registra- tion of Mp313E parental line of maize. Crop Sci. 30:1378.

14. Scott, G. E., and Zummo, N. 1990. Preharvest kernel infection by Aspergillus flavus for resistant and susceptible maize hybrids. Crop Sci. 30:381-383.

15. Scott, G. E., and Zummo, N. 1992. Registration of Mp420 germplasm line of maize. Crop Sci. 32:1296.

16. Wallin, J. R., Widstrom, N. W., and Fortnum, B. A. 1991. Maize populations with resistance to field contamination by aflatoxin B1. J. Sci. Food Agric. 54:235-238.

17. Widstrom, N. W. 1996. The aflatoxin problem with corn grain. Adv. Agron. 56: 219-280.

18. Widstrom, N. W., Forster, M. J., Martin, W K., and Wilson, D. M. 1996. Agronomic performance in the southeastern United States of maize hybrids containing tropical germplasm. Maydica 41:59-63.

19. Widstrom, N. W., Wilson, D. M., and McMillian, W. W. 1984. Ear resistance of maize inbreds to field aflatoxin contamination. Crop Sci. 24:1155-1157.

20. Wild, C. P., and Hall, A. J. 2000. Primary prevention of hepatocellular carcinoma in developing countries. Mutat. Res. 462:381-393.

21. Williams, W. P., and Windham, G. L. 2001 Registration of maize germplasm line Mp715 Crop Sci. 41:1374-1375.

22. Windham, G. L., and Williams, W. P. 1998 Aspergillus flavus infection and aflatoxin accumulation in resistant and susceptible maize hybrids. Plant Dis. 82:281-284.

23. Windham, G. L., and Williams, W. P. 1999 Aflatoxin accumulation in commercial cor hybrids in 1998. Miss. Agric. For. Exp. Stn. Res. Rep. 22, No. 8.

24. Windham, G. L., Williams, W. P., and Davis, F. M. 1999. Effects of the southwestern corn borer on Aspergillus flavus kernel infection and aflatoxin accumulation in maize hybrids. Plant Dis. 83:535-540.

25. Zuber, M. S., Darrah, L. L., Lillehoj, E. B., Josephson, L. M., Manwiller, A., Scott, G. E., Gaudauskas, R. T., Horner, E. S., Widstrom, N. W., Thompson, D. L., Bockholt, A. J., and Brewbaker. J. L. 1983. Comparison of openpollinated maize varieties and hybrids for preharvest aflatoxin contamination in the southern United States. Plant Dis. 67:185 187.

26. Zummo, N., and Scott, G. E. 1989. Evaluation of field inoculation techniques for screening maize genotypes against kernel infection by Aspergillus flavus in Mississippi. Plant Dis. 73:313-316. 